\title{
Prognostic Values of Tumor Necrosis Factor/Cachectin, Interleukin-1, Interferon- $\alpha$, and Interferon- $\gamma$ in the Serum of Patients with Septic Shock
}

\author{
Thierry Calandra, Jean-Daniel Baumgartner, \\ Georges E. Grau, Mei-Miau Wu, \\ Paul-Henri Lambert, Joop Schellekens, Jan Verhoef, \\ Michel P. Glauser, and the Swiss-Dutch \\ J5 Immunoglobulin Study Group*
}

\author{
From the Division of Infectious Diseases, Department of Intermal \\ Medicine, Centre Hospitalier Universitaire Vaudois, Lausanne, and \\ Department of Pathology, World Health Organization Immunology \\ Research and Training Centre, University of Geneva, Switzerland, and \\ Clinical Bacteriology, State University of Utrecht, The Netherlands
}

\begin{abstract}
Serum concentrations of immunoreactive tumor necrosis factor/cachectin (TNF), interleukin$1 \beta$ (IL-1 $\beta)$, interferon- $\gamma$ (IFN $\gamma$ ), and interferon- $\alpha$ (IFN $\alpha$ ) were prospectively measured in 70 patients with septic shock to determine their evolution and prognostic values. In a univariate analysis, levels of TNF $(P=.002)$ and IL-1 $\beta(P=.05)$ were associated with the patient's outcome, but not IFN $\alpha(P=.15)$ and IFN $\gamma(P=.26)$. In contrast, in a stepwise logistic regression analysis, the severity of the underlying disease $(P=.01)$, the age of the patient $(P=.02)$, the documentation of infection (nonbacteremic infections vs. bacteremias, $P=.03$ ), the urine output $(P=.04)$, and the arterial $\mathrm{pH}(P=.05)$ contributed more significantly to prediction of patient outcome than the serum levels of TNF $(P=.07)$. After 10 days, the median concentration of TNF was undetectable $(<100 \mathrm{pg} / \mathrm{ml})$ in the survivors, whereas it remained elevated $(305 \mathrm{pg} / \mathrm{ml}$, $P=.002)$ in the nonsurvivors. Thus, in patients with septic shock due to various gram-negative bacteria, other parameters than the absolute serum concentration of immunoreactive TNF contributed significantly to the prediction of outcome.
\end{abstract}

Tumor necrosis factor/cachectin (TNF) is a cytokine produced by activated macrophages [1] shown in experimental studies to be a primary mediator of the deleterious effects of endotoxin [2-10]. Recently, in patients with meningococcemia, high serum levels of TNF, interleukin-6, interleukin-1, and interferon- $\gamma$ and low serum levels of fibrinogen were shown to correlate with the severity of the disease [11-13]. So far, the kinetics of TNF serum levels in humans has been determined in healthy volunteers challenged with a single intravenous injection of endotoxin [8]. However, similar data on the evolution of serum levels of TNF have not been obtained in patients with gram-negative bacteremia or with septic shock.

Therefore, we prospectively measured the serum concentrations of immunoreactive TNF in patients with septic shock due mainly to gram-negative organisms, to determine the evolution of the serum levels of TNF during the course of septic shock and to relate these levels to patient outcome. Serum concentrations of immunoreactive interleukin-1 $\beta$ (IL-1 $\beta$ ),

Received 25 July 1989; revised 14 November 1989.

Presented in part at the 28th Interscience Conference on Antimicrobial Agents and Chemotherapy (abstract 1340), Los Angeles, October 1988.

Grant support: 3.825-0.86, Fonds National Suisse de la Recherche Scientifique.

Reprints and correspondence: Dr. Thierry Calandra, Division of Infectious Diseases, Dept. of Internal Medicine, Centre Hospitalier Universitaire Vaudois, CH-10ll Lausanne, Switzerland.

* See Acknowledgment.

The Journal of Infectious Diseases 1990;161:982-987 (c) 1990 by The University of Chicago. All rights reserved. 0022-1899/90/6105-0026\$01.00 interferon- $\alpha$ (IFN $\alpha$ ), and interferon- $\gamma(\mathrm{IFN} \gamma)$ were also measured to study the interplay of these cytokines and TNF in patients with septic shock.

\section{Materials and Methods}

The patients enrolled were part of a prospective, double-blind trial that investigated the efficacy of two IgG preparations for the treatment of gram-negative septic shock. The results of that trial including the detailed information about the study design, the tested IgG preparations, the case review, and data analysis have been reported elsewhere [14]. The type of IgG allocated at randomization had no significant impact on the outcome of patients $(P=.30)$ and on the serum concentrations of cytokines (study entry: $P=.72$ for TNF, $P=.73$ for IL-1 $\beta, P=.55$ for IFN $\alpha, P=.75$ for IFN $\gamma$; day 1 : $P=.10$ for TNF, $P=.74$ for IL-1 $\beta, P=.65$ for IFN $\alpha, P=.74$ for IFN $\gamma$; day 10: $P=.25$ for TNF, $P=.09$ for IL-1 $\beta, P=.37$ for IFN $\alpha, P=.06$ for IFN $\gamma$ ). Therefore, the two treatment groups were pooled for the purpose of the present study.

Patient eligibility. Patients eligible for study were those in septic shock defined by the following two criteria: The first was the presence of shock, defined by a systolic blood pressure $<90 \mathrm{~mm} \mathrm{Hg}$ or a decrease of $>30 \mathrm{~mm} \mathrm{Hg}$ in a hypertensive patient, in the absence of other causes of shock such as hypovolemia, myocardial infarction, or pulmonary embolism. In addition, at least one of the following signs had to be present: oliguria $(<30 \mathrm{ml} / \mathrm{h})$, hypothermia $\left(<36^{\circ} \mathrm{C}\right.$ ), hypoxemia (oxygen tension $<70 \mathrm{~mm} \mathrm{Hg}$ ), metabolic acidosis ( $\mathrm{pH}<7.3$ or base excess $<-10 \mathrm{mmol} / \mathrm{l}$ ), coagulation abnormalities (prothrombin time $<50 \%$ or partial thromboplastin time $>40$ $s$ or elevation of fibrin split products), or thrombocytopenia ( $<100$ $\times 10^{9} / 1$ or a decrease of $>50 \%$ of a previously abnormal value). The second criterion was the presence of an infection, that is, a bacteremia or a microbiologically documented focal infection. The iso- 
lated organism was considered to be the pathogen of sepsis if recovered within a $24-\mathrm{h}$ period before or after the onset of shock. Postmortem positive blood cultures were disregarded. In a few patients all cultures remained sterile, possibly because of the concomitant use of broad-spectrum antibiotics. However, despite sterile cultures these patients were included in the study because their clinical courses were highly suggestive of an ongoing infection.

Serum sampling and cytokines radioimmunoassays. Serum was collected in sterile tubes at study entry (i.e., before the infusion of immunoglobulins) and at days 1 and 10 (in those surviving). Serum samples were aliquoted, coded with numbers, and stored at $-70^{\circ} \mathrm{C}$ until assayed blindly. Serum samples underwent at the most two freeze-thaw cycles before being assayed. Serum TNF, IL-1 $\beta$, IFN $\alpha$, and IFN $\gamma$ were assayed with a competitive inhibition radioimmunoassay (IRE-Medgenix, Fleurus, Belgium) [12]. The limits of detection of these radioimmunoassays were $100 \mathrm{pg} / \mathrm{ml}$ of TNF, $150 \mathrm{pg} / \mathrm{ml}$ for IL-1 $\beta, 1$ unit $/ \mathrm{ml}$ of IFN $\alpha$, and 1 unit $/ \mathrm{ml}$ of IFN $\gamma$. When measured in healthy controls, the serum levels of these cytokines were below the respective limit of detection.

Definitions. The severity of the underlying disease was reported according to the classification proposed by McCabe and Jackson [15]. Death was attributed to septic shock if the patient died of irreversible shock, of a direct consequence of shock (i.e., multiple organ failure), or of a complication of infection (i.e., diffuse hemorrhage related to disseminated intravascular coagulation). Other causes of death were attributed to the underlying diseases.

Statistical analyses. Statistical analyses of clinical and laboratory data were done using the $\chi^{2}$ test or Fisher's exact test for the comparisons of proportions and the Kruskall-Wallis test for comparing intergroup differences. Wilcoxon signed-rank test was used to test the interday difference of the serum levels of cytokines. All reported significance levels are two-sided. A stepwise logistic regression was performed to select the most predictive variables of the patient's outcome and to assess their relative importance in this respect. For this particular analysis using the BMDPLR program, the maximum likelihood ratio method and all other default values were used for selecting the prognostic factors [16].

\section{Results}

Of the 100 patients with septic shock randomized in the study of treatment of gram-negative septic shock with two IgG preparations, 78 patients had sera collected for the measurement of TNF, IL-1 $\beta$, IFN $\alpha$, and IFN $\gamma$. Eight patients were excluded from this study because shock either was not due to sepsis (5) or was not present at study entry (3). Thus, we report here on the prognostic values and on the evolution of the serum levels of these four cytokines in 70 patients with septic shock.

Etiology of septic shock. The pathogens of septic shock were gram-negative bacteria in 54 patients $(77 \%)$ - pure culture in 36 patients and mixed culture in 18. Gram-positive bacteria were isolated in 5 patients $(7 \%)$ and yeasts in $3(4 \%)$. In 8 patients $(11 \%)$ all cultures remained sterile. Of the 70 patients, $41(59 \%)$ were bacteremic, of whom $37(90 \%)$ were infected by gram-negative bacteria (pure gram-negative bac- teremia, 30 patients; mixed gram-negative bacteremia, 7), 3 (7\%) by gram-positive bacteria, and $1(3 \%)$ by a yeast.

Characteristics of the patients at study entry. Of the 70 patients with septic shock, 37 (53\%) survived and $33(47 \%)$ died. The survivors and the nonsurvivors were similar with respect to the following parameters (table 1): age, duration of shock before study entry, body temperature, mean arterial pressure, leukocyte count with differential, thrombocyte count, and alveolar-arterial oxygen difference. In contrast, the two groups of patients differed in gender ratio, severity of the underlying disease, documentation of infection, urine output, and $\mathrm{pH}$. With respect to therapy, a similar proportion of the survivors and of the nonsurvivors were treated with vasopressors, with high-dose corticosteroids, and with appropriate antimicrobial treatment.

Tumor necrosis factor. Immunoreactive TNF was detected in $55(79 \%)$ of 70 patients (figure 1). The median serum levels of TNF at study entry (i.e., before the infusion of immunoglobulins) were higher in the nonsurvivors $(330 \mathrm{pg} / \mathrm{ml}$; range, $<100-3500)$ than in the survivors $(180 \mathrm{pg} / \mathrm{ml}$; range, $<100-1300 ; P=.002$ ). Thus, in patients with septic shock due to various microorganisms, the concentrations of immunoreactive TNF was associated with outcome. The serum levels of TNF did not correlate with duration of shock before study entry ( $r=-.07, P=.59$ ), or with duration of survival in those patients ultimately dying of shock $(r=.04, P=$ .83). Since there was an overlap of the serum levels of TNF measured in the survivors and in the nonsurvivors, we determined the concentration of TNF that would best discriminate these two groups of patients. The best cutoff value of serum TNF was at $250 \mathrm{pg} / \mathrm{ml}$. Indeed, of 42 patients with TNF levels $<250 \mathrm{pg} / \mathrm{ml}, 31(74 \%)$ survived compared with only 6 (21\%) of 28 patients with TNF levels $>250 \mathrm{pg} / \mathrm{ml}(P=$ .00005 ). For predicting survival, this cutoff value of $250 \mathrm{pg} / \mathrm{ml}$ had a sensitivity of $84 \%$ (31/37), a specificity of $67 \%(22 / 33)$, a positive predictive value of $74 \%$ (31/42), and a negative predictive value of $79 \%(22 / 28)$.

In the 54 patients with gram-negative infections, the same correlation was observed between the serum levels of TNF and the outcome of the patients $(P=.02)$. Six of the 8 patients infected with gram-positive organisms or with yeasts had elevated concentrations of TNF $(140,170,180,200,200$, and $530 \mathrm{pg} / \mathrm{ml}$ ) at study entry.

To determine the evolution of the serum levels of TNF during the course of septic shock, TNF was measured at days 1 and 10 after study entry. The median concentration of TNF in the survivors decreased from $180 \mathrm{pg} / \mathrm{ml}$ at study entry, to $150 \mathrm{pg} / \mathrm{ml}$ (range, $<100-600$ ) at day 1 , and to $<100 \mathrm{pg} / \mathrm{ml}$ (range, $<100-400)$ at day $10(P=.57$ and $P=.008$, respectively, when compared with levels of TNF at study entry; figure 2A). In contrast, the median concentration of TNF remained high in the nonsurvivors; it was $330 \mathrm{pg} / \mathrm{ml}$ at study entry, 250 $\mathrm{pg} / \mathrm{ml}$ (range, $<100-1500$ ) at day 1 , and $305 \mathrm{pg} / \mathrm{ml}$ (range, 
Table 1. Characteristics of survivors and of nonsurvivors at study entry.

\begin{tabular}{lccc}
\hline Characteristics & Survivors & Nonsurvivors & $p$ \\
\hline No. of patients & 37 & 33 & \\
Age, y & $52(7-78)$ & $60(21-76)$ & .10 \\
Gender, no. M/no. F & $19 / 18$ & $25 / 8$ & .06 \\
Severity of underlying disease, no. (\%) & & & \\
$\quad$ Rapidly fatal & 0 & $6(18)$ \\
Ultimately fatal & $9(24)$ & $9(27)$ \\
$\quad$ Nonfatal & $28(76)$ & $18(55)$ & .02 \\
Documentation of infection, no. (\%) & & & \\
Bacteremias & $22(59)$ & $19(58)$ \\
Nonbacteremic infections & $8(22)$ & $13(39)$ \\
$\quad$ No organism isolated & $7(19)$ & $1(3)$ & \\
Duration of shock, h & $10(2-36)$ & $12(2-144)$ & .06 \\
Body temperature, ${ }^{\circ} \mathrm{C}$ & $38.2(35.0-40.4)$ & $38.0(34-40.4)$ & .55 \\
Mean arterial pressure, mm Hg & $62(17-97)$ & $62(23-85)$ & .39 \\
Diuresis, ml/h & $30(0-190)$ & $0(0-170)$ & .96 \\
Leukocyte, 10\%/l & $8.2(0.1-14.0)$ & $6.1(0.1-100.0)$ & .48 \\
$\quad \%$ band forms & $20(0-70)$ & $19(0-75)$ & .73 \\
Thrombocyte, 10/1 & $88(17-370)$ & $86(12-400)$ & .75 \\
Arterial pH & $7.40(7.27-7.57)$ & $7.34(7.14-7.52)$ & .007 \\
Alveolar-arterial oxygen difference, mm Hg & $170(15-583)$ & $222(35-575)$ & .09 \\
Vasopressor therapy, no. (\%) & $27(73)$ & $30(91)$ & .11 \\
$\quad$ Dose, $\mu g / \mathrm{kg} /$ min & $7(3-24)$ & $9(2-32)$ & .68 \\
High-dose steroid therapy, no. (\%) & $13(35)$ & $13(39)$ & .90 \\
Appropriate antimicrobial therapy, no. (\%) & $36(97)$ & $32(97)$ & .72 \\
\hline
\end{tabular}

NOTE, All data are median (range) unless specified otherwise.

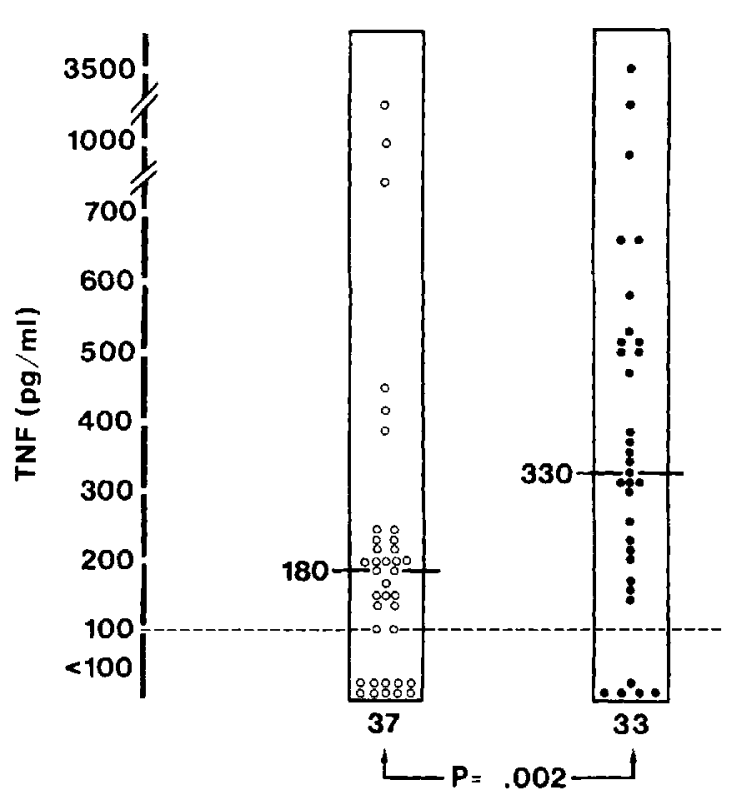

Survivors Nonsurvivors

Figure 1. Serum levels of immunoreactive TNF measured at study entry (before infusion of immunoglobulins) in survivors and nonsurvivors. Horizontal bars represent median concentrations of TNF in each group of patients. Broken line shows limit of detection of radioimmunoassay $(<100 \mathrm{pg} / \mathrm{ml})$.
$<100-480)$ at day $10(P=.78$ and $P=.69$, respectively, when compared with levels of TNF at study entry). As a consequence, at days 1 and 10 the concentrations of TNF remained significantly higher in the nonsurvivors than in the survivors ( $P=.01$ and $P=.002$, respectively). Thus, the serum concentrations of TNF remained elevated in 11 of the 13 nonsurvivors that were still alive at day 10 . Seven of these 11 patients died of irreversible septic shock between 10 and 15 days after study entry; 5 of the 7 had a persistent gram-negative bacteremia, 1 a cavitating gram-negative pneumonia, and 1 an acute respiratory distress syndrome. The other 4 patients died of septic shock after 27-39 days. Their clinical course was characterized by a transient improvement in their hemodynamic profile, followed by a recurrence of septic shock, due to an unresolved primary infection in 3 patients and to a gramnegative pulmonary superinfection in a ventilated patient.

$I L-I \beta, I F N \alpha$, and IFN $\gamma$. The median concentrations of IL$1 \beta$ at study entry were significantly higher in the nonsurvivors (480 $\mathrm{pg} / \mathrm{ml}$; range, $<150-2920)$ than in the survivors $(300$ $\mathrm{pg} / \mathrm{ml}$; range, $<150-3260 ; P=.05$; figure $2 \mathrm{~B}$ ). In contrast to TNF, this difference in the concentration of IL-1 $\beta$ between the nonsurvivors and the survivors did not persist at day 1 $(510 \mathrm{pg} / \mathrm{ml}$ [range, $<150-5250$ ] vs. $450 \mathrm{pg} / \mathrm{ml}$ [range, $<150-4000$ ], $P=62)$ and at day $10(470 \mathrm{pg} / \mathrm{ml}$ [range, $<150-1060$ ] vs. $310 \mathrm{pg} / \mathrm{ml}$ [range, $<150-1460$ ], $P=.12$ ). Se- 
A

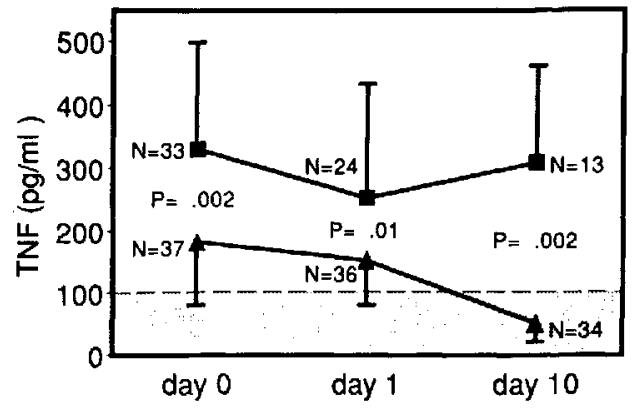

B
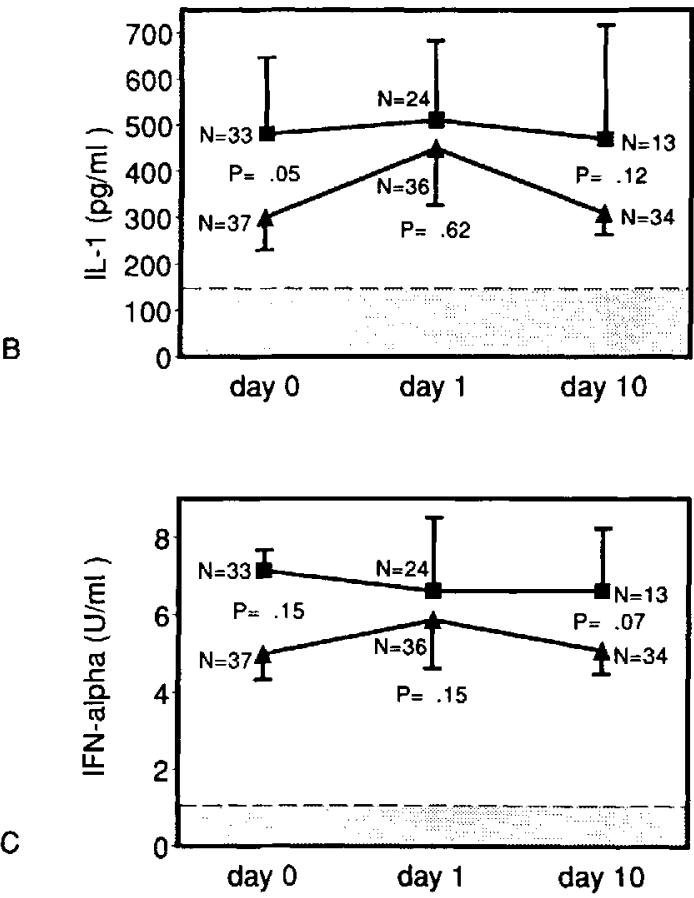

Figure 2. Evolution of serum levels of TNF (A), IL-1 $\beta$ (B), and IFN $\alpha(\mathbf{C})$ in survivors $(\boldsymbol{A})$ and nonsurvivors ( $\mathbf{C})$ during course of septic shock. Concentrations of cytokines are given as median with 95\% confidence interval (vertical bars). Stippled zones represent limit of detection in each radioimmunoassay.

rum levels of IL- $1 \beta$ did not correlate with the serum levels of TNF, when considering either the whole group of patients $(r=-.009, P=.94)$ or those patients with gram-negative infections $(r=-.04, P=.75)$.

Serum concentrations of IFN $\alpha$ (4.98 units/ml [range, $<1-36.9$ ] in the survivors and 7.14 units/ml [range, $<1-16.6$ ] in the nonsurvivors, $P=.15$; figure $2 \mathrm{C})$ and of IFN $\gamma(<1$ unit/ml [range, $<1-19.2$ ] in the survivors and $<1$ unit $/ \mathrm{ml}$ [range, $<1-18.9]$ in the nonsurvivors, $P=27$ ) did not correlate with the patient's outcome and remained unchanged during the course of septic shock. As for IL-1 $\beta$, neither the serum levels of IFN $\alpha(r=-.079, P=.52)$ nor those of IFN $\gamma(r=.161$, $P=.20)$ correlated with the serum levels of TNF.

Logistic regression analysis. Since some of the variables
Table 2. Results of logistic regression analysis.

\begin{tabular}{|c|c|c|c|c|}
\hline Variables & $\begin{array}{l}\text { Coefficient } \\
\text { (C) }\end{array}$ & $\begin{array}{c}\text { Standard } \\
\text { error } \\
\text { (SE) }\end{array}$ & $\begin{array}{l}\mathrm{C}: \mathrm{SE} \\
\text { ratio }\end{array}$ & $P$ \\
\hline Severity of underlying disease & -2.05 & 0.81 & -2.52 & .01 \\
\hline Age & 0.06 & 0.03 & 2.41 & .02 \\
\hline \multicolumn{5}{|l|}{ Documentation of infection } \\
\hline $\begin{array}{l}\text { Nonbacteremic infections } \\
\text { vs. bacteremias }\end{array}$ & 1.93 & 0.86 & 2.24 & .03 \\
\hline $\begin{array}{l}\text { Bacteremias vs. no } \\
\text { organism isolated }\end{array}$ & -1.37 & 1.55 & -0.89 & .38 \\
\hline Urine output & -0.02 & 0.01 & -2.12 & .04 \\
\hline Arterial $\mathrm{pH}$ & -0.09 & 0.04 & -2.03 & .05 \\
\hline TNF & 2.08 & 1.14 & 1.82 & .07 \\
\hline Temperature & -0.06 & 0.03 & -1.68 & .10 \\
\hline Constant & 90.63 & 34.65 & 2.62 & \\
\hline
\end{tabular}

NOTE. The ratio of coefficient to standard error (C:SE) can be read roughly as $t$ statistics. Absolute value $<2$ indicates variable of minor effect in presence of other variables.

are intercorrelated, their joint effect on patient outcome cannot be assessed univariately. Therefore, we performed a stepwise logistic regression analysis to assess the importance of TNF in the presence of other factors. On the basis of data from the literature $[17,18]$ and our exploration of the data of our 70 patients, the following 13 clinical and laboratory variables were evaluated: age, gender, severity of underlying disease, documentation of infection, body temperature, blood pressure, urine output, serum concentrations (of TNF, IL$1 \beta$, and IFN $\alpha$ ), arterial $\mathrm{pH}$, alveolar-arterial oxygen difference, and leukocyte count. In a stepwise manner, 7 of the 13 variables considered initially were included in the model, of which 6 contributed significantly to prediction of patient outcome (table 2). The most significant of these variables were the severity of underlying disease $(P=.01)$, age $(P=.02)$, documentation of infection (nonbacteremic infections vs. bacteremias, $P=.03$, and bacteremias vs. no organism isolated, $P=.38)$, urine output $(P=.04)$, and arterial pH $(P=.05)$. In this statistical model, immunoreactive TNF was at only the limit of significance $(P=.07)$ and the temperature was not statistically significant $(P=.10)$.

To further assess how good the model was, we examined the percentage of correct prediction of patient outcome using either all or only some of the significant variables. With all 6 variables, one could predict the survival of the 70 patients correctly in up to $84 \%$ of the cases. When TNF levels were not taken into account, the correct prediction was still $83 \%$, indicating that TNF contributed marginally to the prediction of patient outcome when the other 5 clinical and laboratory parameters were included. When only severity of underlying disease, documentation of infection, and age were included, patient outcome was predicted correctly up to $75 \%$. The accuracy of the prediction dropped to $62 \%$ if only severity of underlying disease was taken into account. 


\section{Discussion}

In the present study, we examined the evolution and the prognostic value of the serum levels of immunoreactive TNF, IL$1 \beta$, IFN $\alpha$, and IFN $\gamma$ in 70 patients with septic shock due to various microbial agents, mainly gram-negative bacteria. Immunoreactive TNF was detectable in $79 \%$ of our patients with established septic shock. Recently, de Groote et al. [19] measured plasma levels of immunoreactive TNF in 38 patients with presumed sepsis, of whom 14 had gram-negative and 2 had pneumococcal bacteremias. Only $6(16 \%)$ of these 38 patients had detectable TNF levels. In 43 critically ill septic patients, of whom 11 had gram-positive and 9 had gramnegative bacteremias, Debets et al. [20] detected plasma levels of immunoreactive TNF in only 11 patients (25\%). Thus, the data of our present study demonstrate that in contrast to patients with sepsis, most patients with established septic shock due to various gram-negative bacteria have immunoreactive TNF present in their serum. In addition, the detection of elevated TNF levels in the serum of 6 of 8 patients with septic shock due to gram-positive bacteria or yeasts suggests that TNF might also play a role during the development of these infections.

In a univariate analysis, the serum levels of TNF measured at study entry were significantly associated with patient outcome. However, there was a wide overlap between the survivors and the nonsurvivors. Other investigators have also found that levels of biologically active [11] or immunoreactive [12] TNF were associated with outcome in patients with meningococcemia, but they did not determine the relative prognostic value of TNF and of other clinical and laboratory variables.

In order to determine the relative importance of the various prognostic factors of outcome in our patients and to assess whether the serum levels of TNF would remain significant once these factors were taken into account, we performed a stepwise logistic regression analysis. In this analysis, five simple clinical and laboratory variables were significantly as sociated with the outcome of the patients, while serum levels of immunoreactive TNF were at the limit of the statistical significance. Indeed, the percentage of correct prediction of patient outcome was increased only from $83 \%$ to $84 \%$ by adding TNF to these five variables, showing that TNF itself had a negligible impact for prediction. Thus, our observations suggest that in patients with established septic shock, the absolute serum concentration of immunoreactive TNF is not a prime indicator of the severity of the patient's condition and might be of limited value in predicting patient outcome.

Since TNF has been unequivocally shown to be of critical importance in the development of the clinical and humoral manifestations of septic shock in animals $[2-7,21]$ and in humans $[8,22]$ challenged with whole gram-negative bacteria or with lipopolysaccharide, the results of the logistic regression analysis should be cautiously interpreted with regard to the role played by TNF in the pathogenesis of septic shock in our patients. First, measuring serum concentrations of im- munoreactive TNF does not discriminate biologically active TNF from potentially inactive TNF once it is bound to receptors, plasma proteins, or inhibitors. Second, in contrast to rodents $[3,7]$ or primates [6] dying a few hours after an acute challenge with gram-negative bacteria, endotoxin, or recombinant TNF, only $30 \%$ of our patients died within $24 \mathrm{~h}$ of an overwhelming and irreversible septic shock. The other $70 \%$ died of direct or indirect consequences of septic shock at a median of 10 days (range, 2-39) after the onset of septic shock.

In addition, the magnitude and evolution of the serum concentrations of TNF in our patients differed strikingly from those observed in patients with fulminant meningococcal septic shock, in whom the levels of biologically active [11] or immunoreactive TNF [12] were much higher, possibly because meningococcal septic shock follows a particular fulminant course in comparison with septic shock caused by other gramnegative organisms. Moreover, while immunoreactive TNF levels in volunteers were undetectable $4 \mathrm{~h}$ after a single injection of endotoxin [8], 79\% of our patients had detectable le els of TNF $10 \mathrm{~h}$ after the development of shock, probably reflecting differences of infectious stimuli between volunteers and patients. Indeed, we observed two different evolutions of the serum levels of immunoreactive TNF during the course of septic shock. In patients surviving septic shock, the concentrations of TNF had decreased to undetectable levels 10 days after the acute episode, whereas in 11 of the 13 nonsurvivors TNF levels remained elevated.

The persistence of high levels of TNF in the 13 nonsurvivors was related to unresolved primary infections, as shown by the documentation of recurrent gram-negative infections in 6. This could suggest that in patients with septic shock, the persistence of high levels of immunoreactive TNF despite appropriate antimicrobial therapy might be an early clue for a persistent infection as well as for the development of multiple organ failure. Altogether, the present results might therefore indicate that in patients dying from the consequences of septic shock, the host response to TNF production might be somewhat different from that observed in animals after an acute challenge and suggest that once septic shock is established, other variables should be considered for predicting patient outcome.

With regard to levels of other cytokines, we found in a univariate analysis that the serum levels of IL- $1 \beta$ were also significantly higher in the nonsurvivors than in the survivors $(P=.05)$. However, the relation between IL-1 $\beta$ and patient outcome did not remain significant when other prognostic variables were taken into account in the logistic regression analysis. Since it has been shown that the production of IL-1 $\beta$ can be induced by TNF both in vitro [23] and in vivo [24], and since IL-1 $\beta$ experimentally potentiates the lethal effect of TNF [25], we examined the interplay of TNF and IL-1 $\beta$ in the serum of our patients. There was no correlation between serum levels of TNF and of IL-1 $\beta$, either in the overall patient population or in patients with documented gram-negative infections. These results contrast with those observed by Girardin 
et al. [12] and by Waage et al. [13] in children with purpura fulminans, possibly because the correlation between TNF and IL-1 $\beta$ is restricted to meningococcal septic shock.

With regard to IFN $\alpha$ and IFN $\gamma$ serum levels, neither was related to patient outcome. A similar lack of correlation between IFN $\gamma$ and outcome was observed by Waage et al. [13] in patients with meningococcal septic shock, in contrast to the results of Girardin et al. [12] in children with severe meningococcal purpura.

In conclusion, the results of this study showed that immunoreactive TNF and, to a lesser extent, IL-1 $\beta$ are produced in the serum of patients with septic shock due to various gramnegative bacteria, but also due to gram-positive bacteria and to yeasts. Different evolutions of the serum level of TNF were observed in survivors and in nonsurvivors during the course of septic shock. In the survivors, serum TNF progressively decreased to undetectable levels, while it remained elevated for at least 10 days in the vast majority of the nonsurvivors and was often related to the presence of a persistent infection. However, although associated univariately with patient outcome, TNF was shown in a multivariate analysis to contribute less significantly to the prediction of outcome than five simple clinical and laboratory variables.

\section{Acknowledgment}

The principal investigators and participating centers in the SwissDutch 15 Immunoglobulin Study Group were as follows (number of entries into the TNF study): J. Schellekens and J. Verhoef, University Hospital, Utrecht, The Netherlands (28); W. Zimmerli, Kantonsspital, Basel, Switzerland (16); E. Kalter, Sint Radboudziekenhuis, Nijmegen, The Netherlands (15); T. Calandra and M. P. Glauser, Centre Hospitalier Universitaire Vaudois, Lausanne, Switzerland (9); A. Nicole and C. Regamey, Hôpital Cantonal, Fribourg, Switzerland (5); P. Erard, Hôpital des Cadolles, Neuchatel, Switzerland (3); and A. Schaffner, Universitätsspital, Zurich, Switzerland (2).

We thank C. Gysler-Pittet, D. Gretener, and M. Giddey for technical assistance, M. A. Blanc for help with manuscript preparation, and Marc Baudrihaye (IRE-Medgenix, Fleurus, Belgium) for providing the radioimmunoassays for measuring TNF, IL- $1 \beta, \operatorname{IFN} \alpha$, and IFN $\gamma$.

\section{References}

1. Beutler B, Mahoney J, Le Trang N, Pekala P, Cerami A. Purification of cachectin, a lipoprotein lipase-suppressing hormone secreted by endotoxin-induced RAW 264.7 cells. J Exp Med 1985;161:984-995

2. Beutler BA, Milsark IW, Cerami A. Cachectin/tumor necrosis factor: production, distribution and metabolic fate in vivo. J Immunol 1985; 135:3972-3977

3. Tracey KJ, Beutler B, Lowry SF, Merryweather J, Wolpe S, Milsark IW, Hariri RJ, Fahey TJ III, Zentella A, Albert JD, Shires GT, Cerami $A$. Shock and tissue injury induced by recombinant human cachectin. Science 1986;234:470-474

4. Beutler B, Milsark IW, Cerami AC. Passive immunization against cachectin/tumor necrosis factor protects mice from lethal effect of endotoxin. Science 1985;229:869-871
5. Beutler B, Cerami A. Cachectin: more than a tumor necrosis factor N Engl J Med 1987;316:379-385

6. Tracey KJ, Fong Y, Hesse DG, Manogue KR, Lee AT, Kuo GC, Lowry SF, Cerami A. Anti-cachectin/TNF monoclonal antibodies prevent septic shock during lethal bacteraemia. Nature 1987;330:662-664

7. Mathison JC, Wolfson E, Ulevitch RJ. Participation of tumor necrosis factor in the mediation of bacterial lipopolysaccharide-induced injury in rabbits. J Clin Invest 1988;81:1925-1937

8. Michie HR, Manogue KR, Spriggs DR, Revhaug A, O'Dwyer $S$, Dinarello CA, Cerami A, Wolff SM, Wilmore D. Detection of circulating tumor necrosis factor after endotoxin administration. $\mathrm{N}$ Engl J Med 1988;318:1481-1486

9. Waage A, Espevik T, Lamvik J. Detection of tumour necrosis factor-like cytotoxicity in serum from patients with septicemia but not from untreated cancer patients. Scand J Immunol 1986;24:739-743

10. Scuderi P, Sterling KE, Lam KS, Finley PR, Ryan KJ, Ray CG, Petersen E, Slymen DJ, Salmon SE. Raised serum levels of tumor necrosis factor in parasitic infections. Lancet 1986;2:1364-1365

11. Waage A, Halstensen A, Espevik T. Association between tumor necrosis factor in serum and fatal outcome in patients with meningococcal disease. Lancet 1988;1:355-357

12. Girardin E, Grau GE, Dayer JM, Roux-Lombard P, the J5 Study Group, Lambert PH. Tumor necrosis factor and interleukin-1 in the serum of children with severe infectious purpura. N Engl J Med 1988; 319:397-400

13. Waage A, Brandtzaeg P, Halstensen A, Kierluf P, Espevik T. The complex pattern of cytokines in serum from patients with meningococcal septic shock. Association between interleukin 6, interleukin 1, and fatal outcome. J Exp Med 1989;169:333-338

14. Calandra T, Glauser MP, Schellekens J, Verhoef J, the Swiss-Dutch J5 Immunoglobulin Study Group. Treatment of gram-negative septic shock with human IgG antibody to Escherichia coli J5: a prospective, double-blind, randomized trial. J Infect Dis 1988;158:312-319

15. McCabe WR, Jackson GG. Gram-negative bacteremia. I. Etiology and ecology. Arch Intern Med 1962;110:847-855

16. Dixon WJ, ed. BMDP statistical software. Berkeley, CA: University of California Press, 1985

17. Kreger BE, Craven DE, McCabe WR. Gram-negative bacteremia. IV. Reevaluation of clinical features and treatment in 612 patients. Am J Med 1980;68:344-355

18. Bryan CS, Reynolds KL, Brenner ER. Analysis of 1,186 episodes of gram-negative bacteremia in non-university hospitals: the effects of antimicrobial therapy. Rev Infect Dis 1983;5:629-638

19. de Groote MA, Martin MA, Densen P, Pfaller MA, Wenzel RP. Plasma tumor necrosis factor levels in patients with presumed sepsis. JAMA 1989;262:249-251

20. Debets JMH, Kampmeijer R, Van der Linden MPMH, Buurman WA, Van der Linden CJ. Plasma tumor necrosis factor and mortality in critically ill septic patients. Crit Care Med 1989;17:489-494

21. Natanson C, Eichenholz PW, Danner RL, Eichacker PQ, Hoffman WD, Kuo GC, Banks SM, MacVittie TJ, Parillo JE. Endotoxin and tumor necrosis factor challenges in dogs simulate the cardiovascular profile of human septic shock. J Exp Med 1989;169:823-832

22. Suffredini AF, Fromm RE, Parker MM, Brenner M. The cardiovascular response of normal humans to the administration of endotoxin. N Engl J Med 1989;321:280-287

23. Dinarello CA, Cannon JG, Wolff SM, Bernheim HA, Beutler B, Cerami A, Figari IS, Palladino MA Jr, O'Connor JV. Tumor necrosis factor (cachectin) is an endogenous pyrogen and induces production of interleukin 1. J Exp Med 1986;163:1433-1450

24. Dinarello CA, Cannon JG, Wolff SM. New concepts on the pathogenesis of fever. Rev Infect Dis 1988;10:168-189

25. Waage A, Espevik T. Interleukin 1 potentiates the lethal effect of tumor necrosis factor $\alpha /$ cachectin in mice. J Exp Med 1988;167:1987-1992 